\title{
Polybrominated diphenyl ethers: residence time in soils receiving biosolids application
}

\author{
Natasha A. Andrade ${ }^{a^{*}}$, Laura L. McConnell ${ }^{\mathrm{a}}$, Marya O. Anderson ${ }^{\mathrm{a}}$, Alba Torrents ${ }^{\mathrm{a}}$, and Mark \\ Ramirez $^{\mathrm{b}}$ \\ ${ }^{a}$ Department of Civil and Environmental Engineering, University of Maryland, 1153 Martin \\ Hall, College Park, Maryland 20742, USA \\ ${ }^{\mathrm{b}}$ District of Columbia Water and Sewer Authority, 5000 Overlook Avenue, S.W. Washington, \\ District of Columbia 20032, USA \\ Corresponding author phone: 01-301-405-1171; fax: 01-301-405-2585; email: \\ nandrade@umd.edu
}

\begin{abstract}
Polybrominated diphenyl ethers (PBDEs) may enter the environment as a result of accumulation in biosolids followed by application to agricultural lands. No published dissipation studies are available for polybrominated diphenyl ethers in agricultural soils after biosolids application. Therefore, we conducted a three-year study to examine the fate of PBDEs in a smallscale 0.24 ha continuously cropped field after a single biosolids application at 72.3 wet tons/hectare and determined dissipation half-lives for BDE-47+BDE-99 and BDE-209. In addition we conducted a large-scale survey of soils from 26 mostly pasture fields at 10 farms with detailed information on timing and rate of biosolids applications. In the small-scale experiment, PBDE maximum soil concentrations of $43.7 \pm 42.7 \mu \mathrm{gkg}^{-1} \mathrm{~d}$.w. for BDE-209 and $6.05 \pm 7.15 \mu \mathrm{gkg}^{-1} \mathrm{~d} . \mathrm{w}$. for BDE-47+BDE-99 were reached one year after application. We hypothesize that PBDEs were slowly released from the biosolids matrix into the soil over the
\end{abstract}


first year. After three years, median BDE-47+BDE-99 concentrations were approximately equal to pre-application levels while median BDE-209 concentrations remained $~ 129 \%$ above preapplication levels. The estimated residence time from the small-scale experiment was $342 \mathrm{~d}$ for BDE-47+BDE-99 and $861 \mathrm{~d}$ for BDE-209. In the large-scale study, a subset of fields that received a single biosolids application were used to generate another estimate of residence time: $704 \mathrm{~d}$ for BDE-47+BDE-99 and $1440 \mathrm{~d}$ for BDE-209. These longer residence time estimates were utilized in three different first-order decay dissipation scenarios (continuous, limited and no dissipation) to predict PBDE concentration in fields with single and multiple biosolids applications. Results indicate that dissipation occurs primarily in the first two years after application, but residues remaining in the soil after this period are likely to be much more tightly bound and less available for degradation.

Keywords: Residence time, PBDEs, soil, biosolids, half-life, BDE-209

\section{Capsule}

The study calculates PBDE soil residence times in agricultural fields that received biosolids applications; these residence times may be used in terrestrial risk assessments of PBDEs. 


\section{Introduction}

Flame retardant additives (FR) have been added to a wide variety of consumer products to prevent the development of fire for many years. Polybrominated diphenyl ethers (PBDEs) are one class of FRs that have been thoroughly investigated since 1981 when they were found in fish in Swedish waters (Andersson and Blomqvist, 1981). Much attention has been paid to these chemicals due to their ubiquitous presence in animal and human tissues (ATSDR, 2015 and references therein) and their possible toxic impacts, particularly on the liver, reproductive and nervous systems (ATSDR, 2015). PBDEs production occurs in three commercial formulations, c-penta-BDE, c-octa-BDE, and c-deca-BDE, which are named after the average degree of bromination of the congeners they contain. These commercial formulations have been used in furniture foam (c-penta-BDE), electronic office equipment (c-octa-BDE), and in textiles (c-decaBDE) for example (UNEP, 2009; UNEP, 2015). The lower molecular weight congener formulas, c-penta-BDE and c-octa-BDE, pose a greater risk and are more bioactive (McDonald, 2002; UNEP, 2009). Consequently, they were added to the list of persistent organic pollutants in Annex A of the Stockholm convention (UNEP, 2009). Their production and use are now widely limited worldwide (Jinhui et al., 2015; UNEP, 2006; UNEP, 2007; UNEP, 2009; U.S. EPA, 2009). BDE-209, the major congener in c-deca-BDE is listed as a chemical of concern (along with other PBDEs) (UNEP, 2015). C-deca-BDE is undergoing a voluntary phase-out in the U.S. since 2010 and some states have imposed some restrictions on its manufacture and use (UNEP, 2015). Even with reduction in manufacture and use throughout the world, their slow release from consumer products into the environment will continue for many years. 
PBDEs are persistent and resist environmental breakdown via biological, chemical, and photolythic processes due to the chemicals' hydrophobic nature and large molecular sizes (Shen and Wania, 2005). Moreover, engineered wastewater facilities are not specifically designed to remove such pollutants. PBDEs therefore can be found widely in environment, engineered systems, and tend to partition to soil and biosolids. While biosolids application is a sustainable way to raise organic carbon content and increase yield in agricultural fields, biosolids can contain significant levels of PBDEs (Andrade et al., 2015; Gorga et al., 2013; Hale et al., 2001; Nylund et al., 1992; U.S. EPA, 2009). Unsurprisingly, it has been established that biosolids application increases PBDE concentrations in receiving soils (Andrade et al., 2010; Eljarrat et al., 2008; Lozano et al., 2012). Regardless of pathway, elevated PBDE concentrations in agricultural soils potentially poses risks to local terrestrial ecosystems. It is estimated that in the U.S., 7,180,000 dry tons of biosolids were produced in 2004 (NEBRA, 2007) and the production is expected to increase due to urbanization and population growth. Around 55\% of that total was applied to U.S. soils, while the rest was disposed of in landfills, disposal units, or incineration facilities (NEBRA, 2007). Understanding the residence time and bioavailability of PBDEs in the soil environment is important primarily due to their persistence in the terrestrial organisms and bioaccumulative characteristics (Env. Canada, 2010; Gaylor et al., 2014; Nyholm et al., 2010; Sellstrom et al., 2005).

While there are published studies on the fate and levels of PBDEs in soils that have received biosolids application, such studies have only provided information about one point in time, or changes over short periods of time (Eljarrat et al., 2008; Rhind et al., 2013; Xia et al., 2010). This makes it difficult to evaluate the fate of these chemicals on the environment as the temporal trends are not fully understood. This was recently highlighted as an important knowledge gap for 
PBDEs (Law et al., 2014). In this study, authors intended to address this knowledge gap by estimating the soil residence time of PBDEs.

The main objective of this study was to determine, in agricultural fields, the residence time of selected PBDE congeners in surface soil following a single or multiple biosolids applications. Results from a small-scale field with a single controlled biosolids application that was monitored for three consecutive years were compared with results from a survey of 23 large-scale fields that were sampled in 2006 (Andrade et al., 2010) and in 2009. Agricultural large-scale fields that were managed by farmers/owners were divided in three categories: fields that received multiple biosolids applications, fields that received a single biosolids application, and fields that never received biosolids application. Analyzing results from both the small-scale and large-scale fields provides insights on time concentration trends, surface soil residence times, and the complex behavior of organic pollutants in soils. Our extensive sampling also provides a clear indication of spatial variability and cautions results from studies with very limited samples.

\section{Materials and methods}

\subsection{Small-scale field experimental design}

A 0.24-ha field (Sunnyside fine sandy loam) located in Beltsville, MD received a single limestabilized Class B biosolids application in July 18, 2006. Biosolids originated from a large MidAtlantic Nutrient Recovery Facility (NRF) (new term for the facility formerly known as wastewater treatment plant). This NRF receives mainly residential wastewater, but also receives industrial wastewater. A triplicate sample of the applied biosolids was collected before 
application. Biosolids were freshly produced and delivered to the field one week before the application where they were stored under a tarp on the field until application. The full experimental design of this study has been previously published (Lozano et al., 2012). In short, the field was divided into eight subplots that were alternately tilled and left untilled following biosolids application. The untilled subplots were latter disked during the first planting after biosolids application. A manure spreader applied 72.3 wet tons/hectare of biosolids, and tilling (12 in deep) was performed one day after biosolids application according to subplot assignments. A total of 40 samples for each pre-established sampling event were collected across the entire field plus two control samples were collected outside the field.

Surface soil samples were collected before application (May 30, 2006; $n=5$ ); one month (August 16, 2006; $n=26$ ); four months (November 14, 2006; $n=11$ ); 8 months (March 14, 2007; $n=17$ ); 1 year (July 18, 2007; $n=38$ ); 2 years (June 27, 2008; $n=26$ ); and 3 years (July 31, 2009; $n=33$ ) after biosolids application. Soybeans, alfalfa, and corn were planted in the first, second, and third years, respectively. Soil sample collection points were geolocated and recorded using a field GPS instrument (Trimble, Westminster, GeoExplorer Series). The spatial analysis was performed using ArcMap (ESRI GIS and Mapping Software, Vienna, VA). All satellite imagery was obtained from USDA Geospatial Data Gateway (Geo. Data Gateway). Surface soil samples were collected to a depth of approximately $7.6 \mathrm{~cm}$ using an $\mathrm{N}-2$ Handle (Clements Associates Inc. (JMC Soil Samplers), Newton, JMC N-2 Handle PN003) sampler with attached zerocontamination tube (Clements Associates Inc. (JMC Soil Samplers), Newton, PN014). Soil samples were a composite of three cores that were each collected in a $30 \mathrm{~cm}$ diameter area around the collection point. 


\subsection{Large-scale fields experimental design}

Soil samples were collected on May $25^{\text {th }}$ and May $26^{\text {th }}$ of 2009 from farms in Virginia that had previously been sampled in 2006 (Andrade et al., 2010). A total of 27 fields were targeted for sample collection with the following characteristics: a) 13 sites that received multiple biosolids application over up to 16 years; b) 10 sites that received a single biosolids application within four years; and c) 4 sites that had never received a biosolids application.

All selected fields, except for two (which were planted with soybeans and corn), were pasture fields for cattle to graze or undisturbed/untilled hay fields. All fields receiving biosolids application had received at least one biosolids application from the same NRF that was the source of biosolids for the small-field experiment.

Surface soil samples were collected as described previously and the number of samples collected per field varied with the size and shape of the field. In total 170 samples were collected from these fields. Samples contained in zero contamination plastic liners were labeled appropriately and were stored temporally on ice until transfer to a freezer $\left(-30^{\circ} \mathrm{C}\right)$ prior to processing and analysis.

\subsection{Sample processing}

Soil samples were kept frozen and in the dark until preparation for extraction. Prior to processing, samples were thawed overnight and allowed to reach room temperature. Samples were then sieved $(2 \mathrm{~mm})$ to remove grass, rocks, worms, and other debris. Between samples the sieve was washed, dried, and rinsed with acetone and allowed to air-dry. A sub-sample of 
approximately $10 \mathrm{~g}$ was dried by mixing with anhydrous sodium sulfate (J.T. Baker, Phillipsburg, NJ) using a mortar and pestle. It was then split into two approximately equal portions and placed into two $50 \mathrm{~mL}$ Teflon centrifuge tubes (Nalgene, Rochester, NY). Each tube was extracted with $15 \mathrm{~mL}$ and $10 \mathrm{~mL}$ of dichloromethane (DCM) (Acros, Morris Plains, NJ) for the first and second extractions respectively. Decachlorobiphenyl (PCB-209) (Cambridge Isotope Laboratories Inc., Andover, MA) was used as extraction surrogate. All sample processing was conducted in a laboratory with light protection to prevent photodegradation of PBDEs.

Extraction was performed with a vortex mixer (Fisher Scientific, Fairlawn, NJ) at a speed of $2500 \mathrm{rpm}$ for 2 minutes. Samples were then centrifuged for 5 minutes at the speed of $5000 \mathrm{rpm}$ and the solvent decanted. Extract was concentrated using a gentle stream of $\mathrm{N}_{2}$, cleaned up using a 2-g alumina Superclean N-alumina SPE cartridge (Supelco, Bellefonte, PA) (pre-rinsed with $6 \mathrm{~mL}$ of $\mathrm{DCM}$ ), eluted with $6 \mathrm{~mL}$ of $\mathrm{DCM}$, and re-concentrated to $1-\mathrm{mL}$. The extract was then solvent exchanged to hexane. An internal standard $\left({ }^{13} \mathrm{C}_{12} 2,2^{\prime}, 3,4,4^{\prime}, 5^{\prime}\right.$ - hexachlorobiphenyl) (Cambridge Isotope Laboratories Inc., Andover, MA) was added to the extract.

\subsection{Sample analysis}

Eight PBDE congeners were selected for analysis, BDE-28, BDE-47, BDE-99, BDE-100, BDE-153, BDE-154, BDE-183, and BDE-209 (Cambridge Isotope Laboratories Inc., Andover, MA). These analytes were chosen for their prior detection in environmental samples as well as their presence in commercial formulations of PBDEs (de Boer et al., 2003; de Wit, 2002; Law et al., 2014). All sample extracts were analyzed using an Agilent 6890 gas chromatograph (GC) 
coupled with an Agilent 5975 mass selective detector (MSD) (Agilent Technologies Inc., Wilmington, DE) in electron capture negative ion chemical ionization (ECNI) mode with methane as the ionization gas. An Agilent capillary column (DB-5-MS) had a length of 15m, nominal diameter of $0.25 \mathrm{~mm}$, and nominal film thickness of $0.1 \mu \mathrm{m}$ (J\&W Scientific, Folsom, CA). The carrier gas was helium with a constant flow of $1.6 \mathrm{mLmin}^{-1}$. The oven temperature program was as follows: $48^{\circ} \mathrm{C}$ for 3 minutes, $20^{\circ} \mathrm{C} \min ^{-1}$ to $210^{\circ} \mathrm{C}, 25^{\circ} \mathrm{Cmin}^{-1}$ to $310^{\circ} \mathrm{C}, 310^{\circ} \mathrm{C}$ for 5 minutes. Sample injection volume was $1 \mu \mathrm{L}$. A PTV (Programmable Temperature Vaporizing) inlet was used with the following temperature program: $48^{\circ} \mathrm{C}$ for 0.45 minutes and then ramped at a rate of $600^{\circ} \mathrm{Cmin}^{-1}$ to $300^{\circ} \mathrm{C}$ and held for 23 minutes. The inlet also had a pulse pressure of $280 \mathrm{kPa}$. The GC-MS interface was kept at a temperature of $300^{\circ} \mathrm{C}$. Sample concentrations were quantified using the internal standard method and a five point calibration curve.

\subsection{Quality control}

Method detection limits (MDLs) were calculated as previously published (Andrade et al., 2010) using sand as a reference matrix and using EPA 40 CFR Part 136 Appendix B as guideline. MDLs ranged from 0.38 to $6.02 \mu \mathrm{gkg}^{-1}$ d.w. All datasets were treated equally and soil and biosolids samples for which the surrogate recovery was below $70 \%$ were not included in the data analysis.

\subsubsection{Small-scale field}


Sand surrogate (PCB-209) recoveries averaged $72 \pm 27 \%(n=62)$. Matrix surrogate recoveries $(n=232)$ averaged $86 \pm 11 \%$. Sand samples that were spiked with known amounts of PBDEs resulted in recoveries ( $n=57$ ) from 82 to $91 \%$ for all congeners except BDE-209, which had an average recovery of $69 \%$. Matrix congener recoveries ranged from $(n=50) 65$ to $84 \%$ for all congeners except BDE-209 which averaged 92\%. Matrix congener duplicates $(n=54)$ ranged between 1.0 to $12 \%$ difference. PBDE concentrations were below the MDL in all blanks ( $n=31)$.

\subsubsection{Large-scale field}

Average soil matrix surrogate recovery $(n=153)$ was $75 \pm 3.2 \%$, while matrix BDE-28, BDE47, DBE-99, BDE-100, BDE-154, BDE-153, BDE-183 congener recoveries ranged from 62 to $69 \%$ and BDE-209 matrix recovery averaged $89 \%(n=9)$. Sand congener recoveries varied from 76 to $80 \%$ for all congeners while BDE-209 recovery was $52 \%(n=9)$. Lab duplicates were run and they were $(n=8)$ within $2.8 \%$ each other with the exception of BDE-209 which had a \% difference of $13 \%$. Field duplicate samples were collected and analyzed and resulted in congener $\%$ differences of $11 \pm 6.4 \%$ for all congeners. PBDEs were below the MDL in all blank samples $(n=10)$.

\section{Results and discussion}

\subsection{General Trends}

\subsubsection{Biosolids}


Average PBDE concentrations in the biosolids before field application were $1500 \pm 231$ and $371 \pm 17.1 \mu \mathrm{gkg}^{-1} \mathrm{~d} . \mathrm{w}$. for BDE-209 and BDE-47+BDE-99 respectively $(n=6)$. Since BDE-47 and BDE-99 have similar chemical properties, are present in the penta-BDE commercial formulation, and are the major components of the Penta-BDE commercial mixture, we will report the sum of the two congeners. Concentrations are in general agreement with levels found in other parts of the world (Clarke and Smith, 2011). Three congeners, BDE-209, BDE-47, and BDE-99 were detected in all biosolids samples while BDE-28, BDE-100, BDE-154, BDE-153, and BDE-183 were present in very low levels or below detection limits.

\subsubsection{Small-scale field}

Surface soil samples were collected periodically from 50 locations within the field over three consecutive years to establish a relationship between biosolids application time and PBDEs' soil concentrations. Congeners BDE-209 and sum of BDE-47 and BDE-99 contributed to $82 \pm 8.5 \%$ and $8.6 \pm 4.8 \%$ respectively of the total PBDE concentration in all soil samples $(n=156)$. Soil concentrations exhibited significant spatial variability (with RSDs up to 90\%) throughout the field as expected in heterogeneous soil biosolids application (Lozano et al., 2012). Control soil collected from outside the field before biosolids application and throughout the 3-yr sampling period had PBDE concentrations below the MDL for all congeners with the exception of BDE209, which had an average concentration of $10.7 \pm 2.94 \mu \mathrm{gkg}^{-1} \mathrm{~d} . \mathrm{w} .(n=8)$. Pre-application levels inside the field were also below detection or below quantification limit for all BDEs, except for BDE-209 with an average concentration of $6.87 \pm 0.77 \mu \mathrm{gkg}^{-1}$ d.w. $(n=5)$. Measured PBDE 
concentrations in soil were higher after biosolids application and reached maximum concentrations one year after application. Maximum average concentrations $(n=38)$ were $43.7 \pm$ 42.7 and $6.05 \pm 7.15 \mu \mathrm{gkg}^{-1} \mathrm{~d} . \mathrm{w}$. for BDE-209 and sum of BDE-47 and BDE-99, respectively (Fig. 1). Median maximum concentrations were 27.9 and $2.39 \mu \mathrm{gkg}^{-1}$ d.w. for BDE-209 and sum of BDE-47 and BDE-99 respectively.
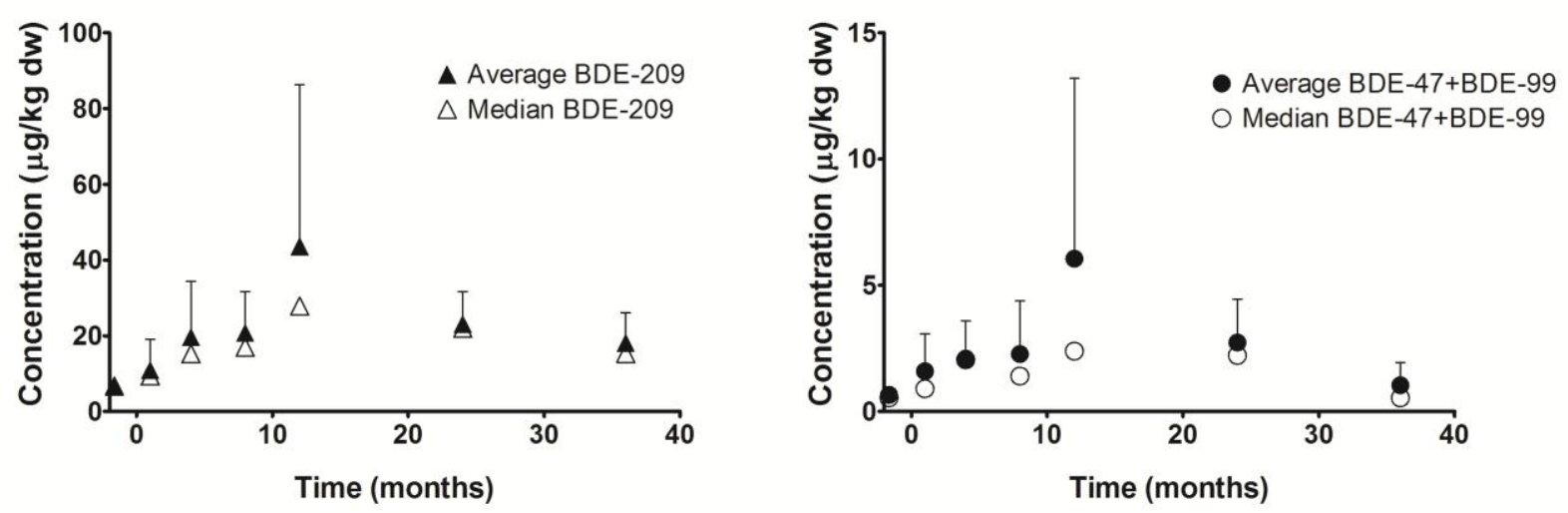

Fig. 1 BDE-209 and BDE-47+BDE-99 average (with standard deviation) and median of concentrations at different sample collection times for the small-scale experiment. Time zero in the scale represents the day of biosolids application. Samples were collected before the application (-49 d) and six times over 36 months after biosolids application.

Sampling sites were recorded by a field GPS instrument and samples were collected at the same sites throughout the 36-months (3-yr) experiment. This approach provided the opportunity to examine temporal and spatial trends across the field (Fig. 2). Results indicate that complete mixing of the biosolids into the soil matrix requires approximately one year from the date of application. This is despite the incorporation of the biosolids after application because of subsequent planting of the soil. Maximum soil concentrations were reached after approximately 
one year then slowly declined, with detectable levels remaining after 36 months (Fig. 2). For BDE-209, average concentrations after 36 months were $164 \%$ higher than average background concentrations. For the sum of BDE-47 and BDE-99, levels were 57\% higher than averages background (MDLs) at 36 months (Fig. 1). After three years, median concentrations of BDE47+BDE-99 approximately equaled pre-application levels (below quantification limit), while median BDE-209 concentrations remained about 129\% higher than at the beginning of the experiment. An in-depth discussion about the possible reasons for the decrease in concentration after 36 months is provided in section 3.3.2 of this article. 


\section{Small-scale Field Temporal Trend}
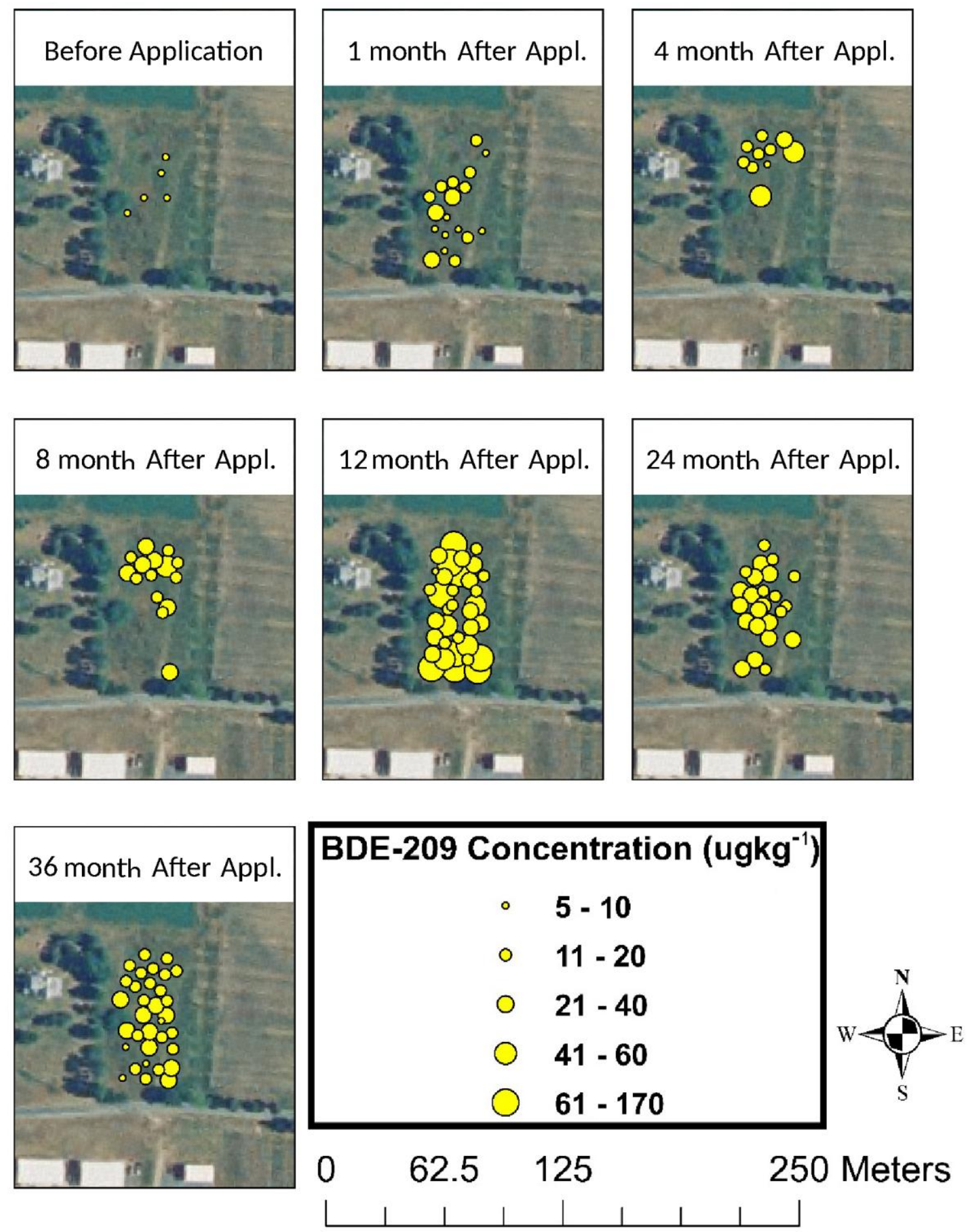

Fig. 2 BDE-209 concentration ( $\mu \mathrm{gkg}^{-1}$ d.w.) in each sampling location for each of the sampling periods. 
The observed increase in PBDE concentrations during the first year is likely due to the mixing of the biosolids material and the partitioning of PBDEs to soil particles. This indicates that there is a time lag between application and complete soil incorporation. A similar trend has been reported for the soil incorporation of triclosan and triclocarban upon biosolids land application (Lozano et al., 2012). Biosolids are generally applied with a manure spreader in large chunks thrown on to the surface of the field. Even with mechanical incorporation of the biosolids into the soil after application and subsequent planting of the field, the biosolids chunks are not completely assimilated into the soil matrix. These biosolids chunks harden into rock-like material and may have been inadvertently sieved out of the soil samples during processing. It is also possible that the non-homogenous application of the biosolids resulted in unrepresentative sampling during the initial sampling dates. It is likely that several wetting and drying cycles of the biosolids-applied soil are needed for the complete incorporation of the biosolids. As the biosolids chunks break down and become part of the soil, PBDEs are released and concentrations of PBDEs in the soil column increase. When biosolids are completely incorporated into the soil, measured concentrations are expected to reach maximum levels. However, concentrations may never reach a theoretical predicted concentration based on application rate, as during the incorporation process, dissipation of PBDEs occurs concurrently.

\subsubsection{Large-scale field}

A total of 26 fields from 10 farms that were previously sampled in 2006 (Andrade et al., 2010) were re-sampled in 2009. Individual fields were classified in three categories: multiple, 
single, and zero biosolids applications. Consistent with previous results, BDE-209, BDE-47, and BDE-99 were the major components of the total PBDE profile in all the fields that had received biosolids applications. The BDE-209 median concentration in fields that never received biosolids application was $3.01 \mathrm{\mu kgg}^{-1} \mathrm{~d} . \mathrm{w} .(n=30)$, consistent with levels found in the small-scale field experiment background levels. In fields that had received a single biosolids application the median was $20.7 \mu \mathrm{gkg}^{-1}$ d.w. $(n=64)$; and in fields with multiple biosolids applications the median was $101 \mathrm{\mu gkg}^{-1}$ d.w. $(n=70)$. The median BDE-47+BDE-99 concentrations in fields with zero, single, and multiple applications were $0.53,1.45$, and $8.97 \mu \mathrm{gkg}^{-1}$ d.w., respectively. These results are in agreement with previous studies that concluded application of biosolids containing PBDEs increases soil PBDE concentrations and the increase is dependent on the number of applications the field receives, indicating accumulation of PBDEs in soils (Andrade et al., 2010; Eljarrat et al., 2008; Xia et al., 2010).

\subsection{Geospatial analysis and management practice effects}

\subsubsection{Small-scale field}

Prior to application, the field was divided into eight columns that were alternately tilled and left untilled (all columns were disked at the time of planting) which allowed investigation of possible effects of management practice on PBDE concentration in soil. It is likely that disked or tilled soil may facilitate the distribution of the biosolids material further down into the soil column. This would result in more effective mixing and thereby a "dilution effect" may be observed resulting in lower PBDE concentrations. However, in this investigation, differences in 
PBDE concentration between the tilled and untilled subplots were not statistically significant $(\mathrm{t}$ test, $p=0.57$ for BDE- 209 and $p=0.56$ for BDE- $47+\mathrm{BDE}-99$ ). It is likely that the disking of the entire field negated some of the effect that could be observed by the original design. Because of this lack of statistical difference, it must be concluded that in this field, management practices did not influence distribution of PBDEs in soil.

\subsubsection{Large-scale fields}

All sampling locations were recorded using a field GPS instrument. In an effort to detect within-field variability, possible discrepancies with written records obtained from the biosolids application contractor, or individual field peculiarities, spatial analysis tools were utilized. For example, in Fig. 3, two fields that received a single biosolids application are delineated with red boundaries. After geospatial analysis of PBDE concentration results, it became clear that the low concentrations observed at three locations in the western field were due to the presence of prescribed buffer zones around the small creek that runs through the field. Once this inconsistency was detected, these points could be removed from the average concentration calculations. This resulted in PBDE averages in the western field that were compatible with other fields that received a single biosolids application.

Fig. 3 Impact of the field geography on the concentration of PBDEs (BDE-47+BDE-99+BDE209 in $\mu \mathrm{gkg}^{-1}$ d.w.) 
In another location, three fields were also analyzed to identify some unexpected results in the dataset. Fields A and B were intensely managed (corn and soybeans) during the years prior to sample collection. A third field (C) was located nearby and managed as a pasture field. This situation provided to be an opportunity to examine field management impact on contaminant concentration. The two fields (A and B) were located near each other on the same farm, and received similar application rates of biosolids over the years (total biosolids application rate within $8.21 \%$ of each other). They had corn and soybeans planted with full tillage of the fields during the sampling years. These fields were compared with field C (pasture), which received biosolids application approximately $22.4 \%$ higher than the average application of the other two fields (Table 1).

The BDE-209, median concentration for fields A and B were 72.7 and $65.4 \mu \mathrm{gkg}^{-1}$ d.w. respectively, while median BDE-209 concentration for field C was $232 \mu \mathrm{gkg}^{-1}$ d.w. The same trend was observed for BDE-47+BDE-99, with median concentrations of 5.17, 6.86, and 45.7 $\mu \mathrm{gkg}^{-1}$ d.w. for fields A, B, and C respectively. Though the application rate was higher for field $\mathrm{C}$, this alone may not explain the much higher PBDE concentrations found in this field. Since fields A, B, and C are located very close to each other they would be exposed to similar environmental conditions that may produce similar volatilization, photodegradation, and microbial degradation rates. However, fields that are intensely managed, such as is the case for fields A and B, could see an increased dissipation rate as compared to fields that are treated as pasture (such as field C). Full tillage of the soil over the years may enhance dissipation processes, such as mixing into lower soil layers (which would results in a dilution effect since the samples in this study were the top $7.6 \mathrm{~cm}$ ). Volatilization and photodegradation may also be enhanced due to atmospheric exposure of the deep soils after tillage. Full tillage may also cause 
more soil and residue movement such as wind-blown dust, erosion and removal by harvested plants (Ahn et al., 2006; Env. Canada, 2010; Melymuk et al., 2012; Nie et al., 2015). All these processes combined may explain the lower observed concentrations in A and B compared to field C.

\section{Table 1}

Application rates, field crop, and PBDE median concentrations for three co-located large-scale fields.

\begin{tabular}{ccccc}
\hline Field & $\begin{array}{c}\text { Application Rate } \\
\left.\text { (dry tonha }^{-1}\right)\end{array}$ & Field Crop & $\begin{array}{c}\text { BDE-209 Median } \\
\text { Conc. }\left(\boldsymbol{\mu g k g}^{-1}\right. \\
\text { d.w.) }\end{array}$ & $\begin{array}{c}\text { BDE-47+BDE-99 } \\
\text { Median Conc. }(\boldsymbol{\mu g k g} \\
\mathbf{1}\end{array}$ \\
\hline A.w.)
\end{tabular}

\subsection{Residence Time}

\subsubsection{Assumptions}

The major objective of this study was to calculate surface soil residence time of selected PBDE congeners in biosolids-applied soil. Other studies that have assessed the fate of persistent organic pollutants in soils determined persistence by defining the chemicals' half-lives. In contrast, we provide our residence time, which also provides an estimate of the time needed for concentrations of a contaminant to reach $50 \%$ of its initial value. However, residence time is a format that is more easily compared with that of other chemicals which may undergo transformations and movement in the environment. Unlike half-lives, the residence time does not necessarily imply that chemicals undergo degradation. Instead, it includes processes such as 
movement between environmental compartments and dissipation or degradation processes. We employed a pseudo-first order dissipation model to calculate residence time (Equation 1) (Jackson and Eduljee, 1994).

$$
\tau_{0.5}=\frac{-t \times \ln (2)}{\ln \left(\frac{C_{\text {soil }(t)}}{C_{\text {soil }\left(t_{0}\right)}}\right)}
$$

The residence time $\left(\tau_{0.5}\right)$ is calculated using the time in which dilution and transport to other environmental media along with other possible dissipation processes occurred $(t)$, the topsoil concentration at a final time $t\left(C_{\text {soil }(t)}\right)$, and the concentration at the beginning of the considered $\operatorname{period}\left(C_{\text {soil }\left(t_{0}\right)}\right)$.

The study included a number of different farms, with different soils, different applications of biosolids, and etc., so a number of assumptions were made to generate residence times that could be compared. Firstly, we assumed that all records, for both the small-scale field and the largescale fields were correct. Records included, but were not limited to: field size, field shape, soil type, biosolids application rate, biosolids application dates, and source of biosolids. Secondly, as is intrinsic to any field work that relies on unverified data from years past, we made specific assumptions: the concentration of PBDEs in the biosolids applied to fields were the same, independent of date; fields had not received biosolids application before the initial recordkeeping; and fields were categorized into crop or hay/pasture reflecting management practices at the time of sampling. Thirdly, we assumed the average concentration of PBDEs in biosolids applied to the fields ([PBDE]) was 250 and $1500 \mu \mathrm{gkg}^{-1}$ d.w. for BDE-47+BDE-99 and BDE-209, respectively. These concentrations are average PBDE concentrations in biosolids 
measured over six years (2005-2011) from the NRF that provided biosolids to the farms included in the study (Andrade et al., 2015). Several of the large-scale fields sampled for this study received biosolids applications from other NRFs and these biosolids could have significantly different PBDEs concentrations, therefore we excluded from residence time calculations all fields that received biosolids applications from any NRF other than the one thoroughly investigated for this study. Other assumptions included incorporation depth of $7.6 \mathrm{~cm}$ (due to sampling depth) and a common soil density of $1.3 \mathrm{gcm}^{-3}$ (Wolf, 1999) (unchanged density due to biosolids application).

\subsubsection{Small-scale field}

This and a similar study (Lozano et al., 2012) suggest that it can take up to one year for the biosolids, and thus the PBDEs as well, to be fully incorporated into the soil. Therefore, we assumed that during the first year, soil incorporation is taking place and dissipation was not significant (Fig. 1). It is possible that two processes, biosolids incorporation to the soil, and dissipation by transferring to other environmental media, were occurring simultaneously. However, we assumed that the first process is more relevant during the first year and the second was predominant after the first year until the end of the sample collection period. We also assumed that one year after application, all biosolids were incorporated and thus there was no additional release of PBDEs from biosolids into soil.

From assumptions made previously for PBDE biosolids concentration, incorporation depth, and soil density, it is possible to calculate a predicted soil PBDE concentration (Equation 2) for 
BDE-209 and for BDE-47+BDE-99. The value of $\mathrm{C}_{\text {pred }}$ was calculated based on the assumption of no dissipation and no movement of PBDE to another media or soil layers.

$\mathrm{C}_{\text {pred. }}\left(\frac{\mu \mathrm{g}}{\mathrm{kg}} \mathrm{d} . \mathrm{W}.\right)=\frac{[\mathrm{PBDE}] \times \text { Application Rate } \times \text { Area }}{\text { Soil Volume } \times \text { Soil Density }}$

The predicted maximum concentration for the small-scale field was 26.9 and $6.65 \mu \mathrm{gkg}^{-1}$ d.w. for BDE-209 and BDE-47+BDE-99, respectively. $\mathrm{C}_{\text {pred }}$ was compared to the median measured concentration in the field one year after biosolids application. For BDE-209, the measured median concentration was $27.9 \mu \mathrm{gkg}^{-1}$ d.w., a value within $4 \%$ difference of the predicted concentration. However, for the sum of BDE-47 and BDE-99, the median concentration was $2.39 \mu \mathrm{gkg}^{-1}$ d.w., approximately $64 \%$ lower than the predicted concentration. This discrepancy for BDE-47+BDE-99 could be due to a higher availability of these lower brominated congeners to move from one environmental phase to another, particularly during the biosolids-soil incorporation period (Env. Canada, 2010; Liang et al., 2010; Nie et al., 2015; Nyholm et al., 2010; Wong et al., 2012).

The residence time, $\tau_{0.5}$, was calculated using equation 1 with the initial concentration defined as the topsoil PBDE concentration measured at one year and the final concentration as the measured PBDE concentration from 2009. Due to variability of the soil data, median concentrations were used for these calculations as they were more representative of the entire dataset. Median residence time calculated for the sum of BDE-47 and BDE-99 was $342 \mathrm{~d}$ or 0.94 yr and for BDE-209, $861 \mathrm{~d}$ or $2.36 \mathrm{yr}$.

Residence times calculated here indicate that field management, soil type, and nature of the application can play an important role. Previous research used an estimation software tool to 
approximate the half-life of PBDEs in soil and concluded that the half-life would be $150 \mathrm{~d}$ for BDE-209, BDE-47, and BDE-99 (Palm et al., 2002). However, once the half-life was utilized in a fugacity model, predicted concentrations in soil were significantly smaller than observed environmental levels. This suggests the $150 \mathrm{~d}$ half-life estimate was lower than actual half-life. In comparison, the residence time reported here is lower than another previously estimated halflife of $12.7 \mathrm{yr}$ (Andrade et al., 2010) that was based on polychlorinated biphenyl data. Soil residence time and half-life are difficult parameters to estimate, as field conditions vary widely. Past attempts at this estimation offered quite different results, therefore it is difficult to assume that the values presented here are close to reality. However, residence time values presented in this study are based on actual measured field concentrations, and though several assumptions were made, this study used the best available approach for determining this important parameter. Moreover, this study calculated different soil residence times for congeners with different levels of bromination, which more closely reflects previous literature and the differences in chemical properties of the congeners (Shen and Wania, 2005).

The most influential processes that can affect the residence time of these chemicals in soil are: 1) microbial degradation, 2) photodegradation, 3) volatilization, 4) wind erosion of soil, and 5) movement within the soil. Temperature and rainfall can influence some of these processes and therefore are of importance as well. Results from earlier research have indicated PBDEs are not expected to undergo extensive degradation in topsoil. This has been demonstrated for BDE-47 and BDE-99 in a study with urban soil from Canada that was carried out for 360 days (Wong et al., 2012). Some studies have shown that selected PBDE congeners adsorb strongly and irreversably to soil, making them unavailable for degradation (Liu et al., 2012; Olshansky et al. 2011). Ahn et al. (2006) demonstrated that photodegradation of BDE-209 does occur when 
attached to sediments, suggesting half-lifes that ranged from 261 to 408 days when sediment was exposed to sunlight. The authors however, suggested that this process would be most relevant when BDE-209 is attached to mineral aerosols.

The volatility of BDE-47, among other congeners, was investigated by Wong et al. (2012), and it was concluded that during the 360-d experiment. The volatility of BDE-47 started to decrease imediately after PBDE introduction to the soil and continued to decrease until the end of the experiment. The authors associated the decrease in volatilization with the formation of soil-bound residues and sequestration of chemicals into the micropores of the soil (Wong et al., 2012). Although no quantification was reported in the later study, their results suggest that loss of PBDEs by volatilization may be small.

\subsubsection{Large-scale fields}

Following the same protocol as previously stated, predicted soil PBDE concentrations were calculated for each field that received biosolids applications. Predicted concentrations were then compared to measured concentration in each field. For the sum of BDE-47 and BDE-99, the ratio of measured to predicted concentrations (Meas/Pred) was $>1$ in $48 \%$ of fields. For BDE-209, $60.9 \%$ of the fields had Meas/Pred ratios of $>1$. Since the measured concentration was greater than the predicted, calculation of a residence time in these fields was not possible. The higher than predicted concentrations could have been caused by fields receiving biosolids which may have contained higher concentrations of PBDEs because they came from a variety of facilities. It is also possible that some of the fields recorded the application dates and rates erroneously. Additional applications may not have been recorded if a different contractor was used. 
Therefore, for the purposes of this study, results for fields where measured concentrations were greater than predicted were removed from subsequent residence time calculations.

A subset of fields that received a single biosolids applications from the NRF where biosolids have been well-characterized was used to estimate a residence time (Eq. 1) for BDE-47+BDE-99 and for BDE-209. A median residence time of $704 \mathrm{~d}$ or $1.93 \mathrm{yr}$ was calculated for BDE$47+\mathrm{BDE}-99$ ( $n=5$ fields) and of $1440 \mathrm{~d}$ or $3.93 \mathrm{yr}$ ( $n=3$ fields) for BDE-209. To the authors' knowledge, these are the first reported PBDE residence times calculated in active agricultural soils based on field measured data. The residence times of BDE-47+BDE-99 and BDE-209 found in single application large-scale fields are higher than those found in the small-scale field, but within a factor of 2 . The larger residence times for the large-scale fields could be caused by the management practices. The single-application large-scale fields used were all pasture fields which remain largely undisturbed, while the small-scale field had crops throughout the samplecollection period.

\subsubsection{PBDE dissipation scenarios}

To characterize the PBDEs dissipation over time in fields that received multiple applications of biosolids, further analysis was done on sampled fields which received either a single or multiple biosolids applications. Equations 1 and 2 can be used in combination to calculate the predicted soil PBDE concentration after a specific biosolids application, and then calculate the dissipation over time given a specific residence time. Two different residence times were calculated from our field experiments (one for the small-scale field and another for the singleapplication large-scale fields); we chose to use the residence time calculated for the single- 
application large-scale fields. While the small-scale field experiment was more controlled and the applied biosolids were sampled and concentrations characterized, the residence time calculated for the single-application large-scale fields is more representative of the large-scale fields in general. Most of the large-scale fields are pasture and in the same region as the singleapplication large-scale fields. Though there is more variability among soil samples from the large-scale fields, the similarity in location (including soil type) and field management is likely more important.

Predicted concentrations were calculated under a number of scenarios for the remaining 23 fields that received either multiple or single biosolids applications. To accomplish this, the residence time of $704 \mathrm{~d}$ for BDE-47+BDE-99 and of $1440 \mathrm{~d}$ for BDE-209 were used in conjunction with the dates of biosolids applications, applications rates, and the date of sampling.

Dissipation scenarios were: 1) Continuous Dissipation (CD): where PBDEs present in the biosolids were available for dissipation as soon as biosolids were applied to the fields, and remained available until the sampling time; 2) Limited dissipation after one year incorporation (LD): where PBDEs present in biosolids were not available for dissipation until one year after biosolids application, as soil incorporation was a more important process. In this scenario, the PBDEs residues of the first biosolids application became unavailable for dissipation once a second application of biosolids was made to the field. Subsequently, residues for the second application became unavailable for dissipation when a third biosolids application to the field was completed, and so on. Our hypotheses here are that, as observed in the small-scale field, concentrations of PBDEs in the soil will rise during the first year due to the incorporation of biosolids into the soil, and over time, some residues will remain in the soil as they will be unavailable for dissipation due to soil ageing processes. During the ageing process, residues 
become tightly bound to soil particles and become less available for degradation. The third and last scenario is the most conservative of them all: 3) No dissipation (ND): where no dissipation occurred and PBDE concentrations of collected soil samples reflect the predicted concentration due only to single or multiple applications of biosolids.

The predicted concentrations were compared with measured concentrations for samples collected in 2009, and the ratio of Measured/Predicted was calculated (Fig. 4). A ratio equal to one indicates the measured and predicted are equal. Ratios $>1$ indicate slower dissipation rate or other sources of PBDEs to the soil. In Fig. 4, fields were ordered along the x-axis by highest to lowest number of applications and by date of initial application from earliest to latest. An example of the above mentioned calculations is provided in Supplementary Material.

For the lower brominated congeners BDE-47 and BDE-99, fields that received more than two applications resulted in Measured/Predicted ratios that were well above the ratio of one for the CD scenario (Fig 4). In fact, these ratios were higher than those found for BDE-209 for the same scenario and the same fields. This indicates that the assumptions of this scenario do not represent what was measured in the fields. The CD scenario had the highest ratios for fields that had more than two biosolids applications and also for the oldest applications. This indicates that a timedependent immobilization of the PBDEs residues is likely. It seems that for fields that receive more than two biosolids application, the lower brominated congeners accumulated over time, to the point that no dissipation can be expected, or there were other sources of these congeners, such as particle-associated transport or even formation of these congeners from higher brominated forms. Fields that received biosolids application recently (>2005) had Measured/Predicted ratios for all scenarios and for BDE-209 and BDE-47+BDE-99 within a factor of 2 of the unity ratio for all scenarios (with only three exceptions). This demonstrates that 
dissipation occurs primarily during the first 3-4 years after application. This finding is supported by results of the small scale study where degradation was still occurring at three years.
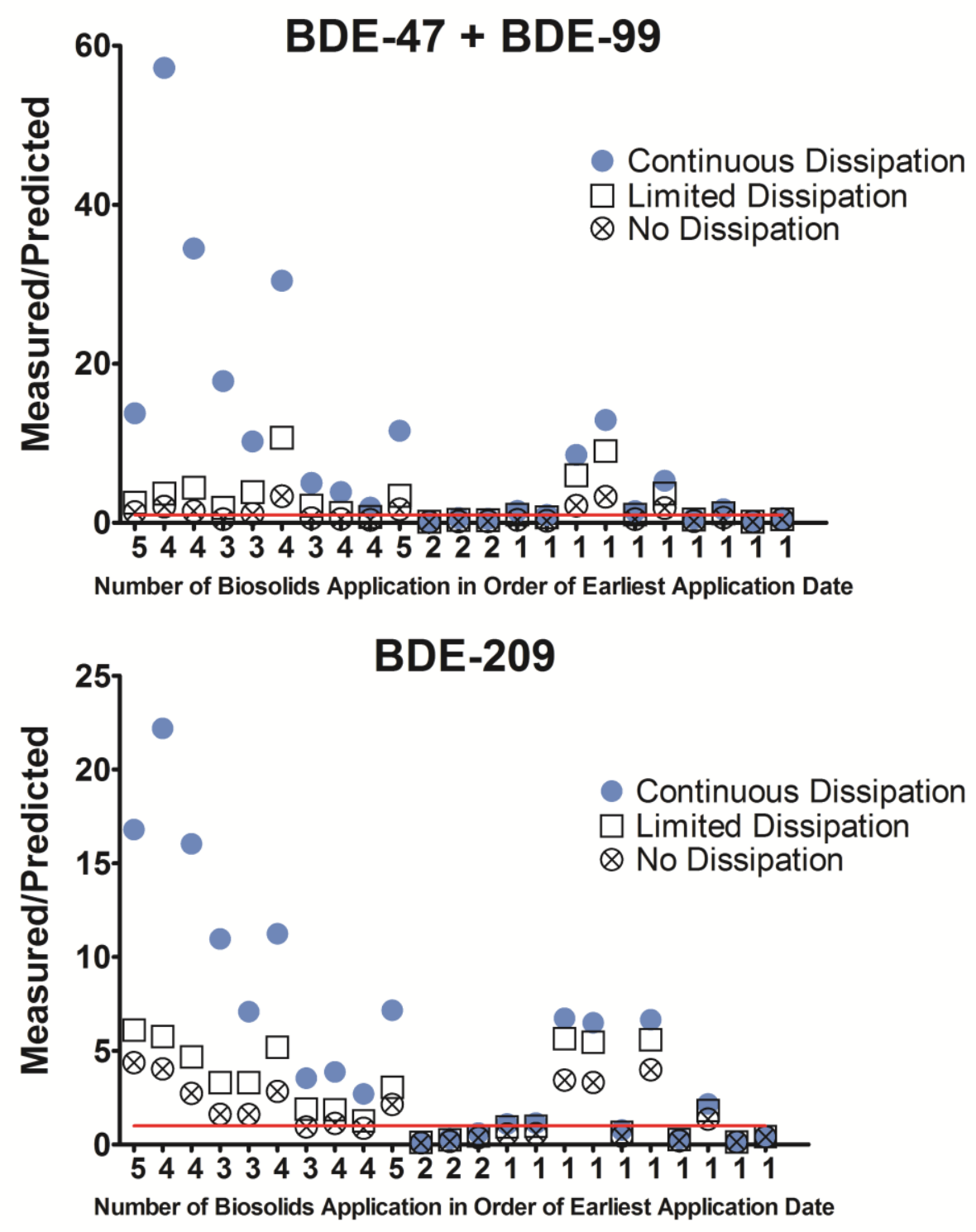

Fig 4. Measured/Predicted ratio for BDE-47+BDE-99 and for BDE-209 for the three scenarios evaluated. Red line at Measured/Predicted $=1$. Fields on the $\mathrm{x}$-axis are ordered by number of biosolids application and also by earliest application date to latest. 
For BDE-209, similar trends were observed. The fields with more and older applications had higher Measured/Predicted ratios and the fields with a single or two applications were within a factor of two of the unity value. According to these results, the limited dissipation scenario is a fairly good assumption of what was measured in the field. However, the scenario that resulted in the best match between the predicted and the measured concentrations was the no dissipation scenario. Since this scenario assumes that no dissipation occurs, it is an unlikely scenario to occur in the environment. However, the fact that this scenario was the best in describing measured field concentrations in this study suggests that either the residence times calculated here underestimated the "real" residence time or the single first-order dissipation assumption may not reflect the actual dissipation that occurs in all fields. A time-dependent adsorption and immobilization where a bi-phasic model of PBDE degradation in soil would likely be more appropriate for calculating dissipation rates, and this should be addressed in future research.

\section{Conclusions}

A comparative study between large-scale agricultural fields and a small-scale experimental field provided a better insight on the factors controlling the fate of polybrominated diphenyl ethers upon biosolids application to agricultural fields. Biosolids application can be quite beneficial to soils, increasing the organic matter and yields. However, persistent contaminants, such as PBDEs, present in biosolids can transfer to soils after application. Our results clearly indicate that biosolids can take up to one year to become completely incorporated into the soil matrix and biosolids-bound PBDE residues are released during this time. PBDEs profiles in soils that receive biosolids applications are similar to PBDEs profiles in biosolids. The extent of 
dissipation during soil incorporation is a strong function of the physicochemical properties of the chemical. For chemicals such as BDE-209, the soil concentration one year after application can be very close to the predicted concentration given a biosolids application. For less persistent chemicals such as BDE-47 and BDE-99, the maximum soil concentration can be far below the predicted concentration. Temporal and spatial variability were shown to be large in both studies, which suggests that a large number of samples may be needed to be representative of an agricultural field. Care should be taken in generalizations with small sample sizes and limited soil characteristics. Large-scale fields sampled in 2006 and 2009 provided insight in the complex nature of biosolids application to agricultural soil and also the interaction of organic pollutants with soil. Estimated median residence time in fields that received a single biosolids application was $704 \mathrm{~d}$ for BDE-47+BDE-99 and $1440 \mathrm{~d}$ for BDE-209. As previously discussed in the literature, different levels of bromination result in different environmental behavior and this is the first study to report such different soil residence times for different congeners. These residence times were incorporated with three first-order dissipation scenarios and then used to predict PBDE soil concentration for 23 other fields. The predicted concentrations were then compared with measured concentrations. Results showed that the scenario which assumed continuous dissipation of chemical residues did not represent the field data well. Both the limited and no dissipation scenarios showed good agreement between predicted and measured concentrations, however, the no dissipation scenario resulted in the best results. Since the no dissipation scenario is probably not accurate in describing actual environmental conditions, we conclude that these chemicals are persistent, and the residence time calculated here may be overestimating actual field dissipation. Possibly, the first-order model may also not be the most representative of field conditions. However, the residence times calculated here are of great 
value to risk assessments as they are solely based on extensive field data. It is important to note that based on field data, we may be still underestimating the soil residence time of PBDEs, so when performing terrestrial risk assessments, conservative assumptions should be made. This unique study offers important information that was previously unavailable to researchers interested in assessing the fate and environmental risks of PBDEs. Further research, measuring long-term trends in soil concentrations are necessary to better understand the fate of these organic chemicals once they are introduced in the environment and cross the urban-agricultural border.

\section{Acknowledgements}

This study was partially supported by the District of Columbia Water and Sewer Authority, Washington DC, and the Agricultural Research Service - US Department of Agriculture laboratories at Beltsville, MD. The authors want to acknowledge and thank the laboratory personnel at the USDA for the support in the analysis of samples.

\section{References}

Ahn, M., Filley, T. R., Jafvert, C. T., Nies, L., Hua, I., \& Bezares-Cruz, J., 2006.

Photodegradation of decabromodiphenyl ether adsorbed onto clay minerals, metal oxides, and sediment. Environmental Science and Technology 40, 215-220.

http://dx.doi.org/10.1021/es051415t.

Andersson Ö, Blomkvist G., 1981. Polybrominated aromatic pollutants found in fish from Sweden. Chemosphere 10, 1051-60. http://dx.doi.org/10.1016/0045-6535(81)90216-2. 
Andrade, N. A., Lozano, N., McConnell, L. L., Torrents, A., Rice, C. P., Ramirez, M., 2015. Long-term trends of PBDEs, triclosan, and triclocarban in biosolids from a wastewater treatment plant in the Mid-Atlantic region of the US. Journal of Hazardous Materials 282, 68-74. http://dx.doi.org/10.1016/j.jhazmat.2014.09.028.

Andrade, N.A., McConnell, L.L., Torrents, A., Ramirez, M., 2010. Persistence of polybrominated diphenyl ethers in agricultural soils after biosolids applications. Journal of Agricultural and Food Chemistry 58, 3077-3084. http://dx.doi.org/10.1021/jf9034496.

Chen, Y., Jinhui, L., Liu, L., Zhao, N., 2012. Polybrominated diphenyl ethers fate in China: A review with an emphasis on environmental contamination levels, human exposure and regulation. Journal of Environmental Management 113, 22-30. http://dx.doi.org/10.1016/j.jenvman.2012.08.003.

Clarke, B. O., Smith, S.R., 2011. Review of 'emerging' organic contaminants in biosolids and assessment of international research priorities for the agricultural use of biosolids. Environment International 37, 226-247. http://dx.doi.org/10.1016/j.envint.2010.06.004.

de Boer, J., Wester, P.G., van der Horst, A., Leonards, E.G., 2003. Polybrominated diphenyl ethers in influents, suspended particulate matter, sediments, sewage treatment plants and effluents and biota from the Netherlands. Environmental Pollution 122, 63-74. http://dx.doi.org/10.1016/S0269-7491(02)00280-4. 
de Wit, C.A., 2002. An overview of brominated flame retardants in the environment.

Chemosphere 46, 583-624. http://dx.doi.org/10.1016/S0045-6535(01)00225-9.

Eljarrat, E., Marsh, G., Labandeira, A., Barcelo, D., 2008. Effect of sewage sludges contaminated with polybrominated diphenyl ethers on agricultural soils. Chemosphere 71, 10791086. http://dx.doi.org/10.1016/j.chemosphere.2011.07.068.

Environment Canada. 2010. Ecological State of the Science Report on Decabromodiphenyl Ether (decaBDE), Bioaccumulation and Transformation; EPA-HQ-OPPT-2010-1039-0022. Accessed $5 / 11 / 2016$.

Gaylor, M.O., Mears, G.L., Harvey, E., La Guardia, M.J, Hale, R.C., 2014. Polybrominated diphenyl ether accumulation in an agricultural soil ecosystem receiving wastewater sludge amendments. Environmental Science and Technology 48, 7034-7043.

http://dx.doi.org/10.1021/es5014032.

Gorga, M., Martinez, E., Ginebreda, A., Eljarrat, E., Barcelo, D., 2013. Determination of PBDEs, HBB, PBEB, DBDPE, HBCD, TBBPA and related compounds in sewage sludge from Catalonia (Spain). Science of the Total Environment 444, 51-59.

http://dx.doi.org/10.1016/j.scitotenv.2012.11.066. 
Hale, R. C., La Guardia, M. J., Harvey, E. P., Gaylor, M. O., Matteson Mainor, T., Duff, W. H., 2001. Persistent pollutants in land-applied sludges. Nature 412, 140-141. http://dx.doi.org/10.1038/35084130.

Jackson, A. P., Eduljee, G. H., 1994. An assessment of the risks associated with PCDDs and PCDFs following the application of sewage sludge to agricultural land in the UK. Chemosphere 29, 2523-2543. http://dx.doi.org/10.1016/0045-6535(94)90055-8.

Jinhui, L., Yuan, C., Wenjing, X., 2015. Polybrominated diphenyl ethers in articles: a review of its applications and legislation. Environ Science and Pollution Research. http://dx.doi.org/10.1007/s11356-015-4515-6.

Law, R. J., Covaci, A., Harrad, S., Herzke, D., Abdallah, M. A.-E., Fernie, K., Toms, L. L., Takigami, H., 2014. Levels and trends of PBDEs and HBCDs in the global environment: status at the end of 2012. Environment International 65, 147-158.

http://dx.doi.org/10.1016/j.envint.2014.01.006.

Liang, X., Zhu, S., Chen, P., Zhu, L., 2010. Bioaccumulation and bioavailability of polybrominated diphenyl ethers (PBDEs) in soil. Environmental Pollution 158, 2387-2392. http://dx.doi.org/10.1016/j.envpol.2010.04.008. 
Liu, W., Cheng, F., Li, W., Xing, B., \& Tao, S., 2012. Desorption behaviors of BDE-28 and BDE-47 from natural soils with different organic carbon contents. Environmental Pollution 163, 235-242. http://dx.doi.org/10.1016/j.envpol.2011.12.043.

Lozano, N., Rice, C.P., Ramirez, M., Torrents, A., 2012. Fate of triclosan and methyltriclosan in soil from biosolids application. Environmental Pollution 160, 103-108. http://dx.doi.org/10.1016/j.envpol.2011.09.020.

McDonald, T. A., 2002. A perspective on the potential health risks of PBDEs. Chemosphere 46, 745-755. http://dx.doi.org/10.1016/S0045-6535(01)00239-9.

Melymuk, L., Robson, M., Helm, P.A., Diamond, M.L., 2012. PCBs, PBDEs, and PAHs in Toronto air: spatial and seasonal trends and implications for contaminant transport. Science of the Total Environment 429, 272-280. http://dx.doi.org/10.1016/j.scitotenv.2012.04.022.

North East Biosolids and Residuals Association (NEBRA), 2007. A national biosolids regulation, quality, end use and disposal survey - preliminary report. https://static1.squarespace.com/static/54806478e4b0dc44e1698e88/t/5488541fe4b03c0a9b8ee09 b/1418220575693/NtlBiosolidsReport-20July07.pdf

Nie, Z., Tian, S., Tian, Y., Tang, Z., Tao, Y., Die, Q., Fang, Y., He, J., Wang, Q., Huang, Q., 2015. The distribution and biomagnification of higher brominated BDEs in terrestrial organisms 
affected by a typical e-waste burning site in South China. Chemosphere 118, 301-308. http://dx.doi.org/10.1016/j.chemosphere.2014.09.062.

Nyholm, J.R., Asamoah, R.K., Van der wal, L., Danielsson, C., Andersson, P.L., 2010. Accumulation of polybrominated diphenyl ethers, hexabromobenzene, and 1,2-dibromo-4-(1,2dibromoethyl)-cyclohexane in earthworm (Eisenia fetida). Effects of soil type and aging. Environmental Science and Technology 44, 9189-9194. http://dx.doi.org/10.1021/es1023288.

Nylund, K., Asplund, L., Jansson, B., Jonsson, P., Litzen, K., Sellstrom, U., 1992. Analysis of some polyhalogenated organic pollutants in sediment and sewage sludge. Chemosphere 24, 1721-1730. http://dx.doi.org/10.1016/0045-6535(92)90227-I.

Olshansky, Y., Polubesova, T., Vetter, W., Chefetz, B., 2011. Sorption-desorption behavior of polybrominated diphenyl ethers in soils. Environmental Pollution 159, 2375-2379. http://dx.doi.org/10.1016/j.envpol.2011.07.003.

Palm, A., Cousins, I. T., Mackay, D., Tysklind, M., Metcalfe, C., Alaee, M., 2002. Assessing the environmental fate of chemicals of emerging concern: a case study of polybrominated diphenyl ethers. Environmental Pollution 117, 195-213. http://dx.doi.org/10.1016/S0269-7491(01)002767.

Polybrominated Diphenyl Ethers (PBDEs) Action Plan. 2009. EPA-HQ-OW-2010-0824-0293, United States EPA. Accessed 5/12/2016. 
Rhind S.M., Kyle, C.E., Ruffie, H., Calmettes, E., Osprey, M., Zhang, Z.L., Hamilton, D., McKenzie, C., 2013. Short-and long-term temporal changes in soil concentrations of selected endocrine disrupting compounds (EDCs) following single or multiple applications of sewage sludge to pastures. Environmental Pollution 181, 262-270. http://dx.doi.org/10.1016/j.envpol.2013.06.011.

Sellstrom, U., De Wit, C.A., Lundgren, N., Tysklind, M., 2005. Effect of sewage-sludge application on concentrations of higher-brominated diphenyl ethers in soils and earthworms. Environmental Science and Technology 39, 9064-9070. http://dx.doi.org/10.1021/es051190m.

Shen, L., Wania, F., 2005. Compilation, evaluation, and selection of physical-chemical property data for organochloride pesticides. Jounal of Chemical Engineering Data 50, 742-768. http://dx.doi.org/10.1021/je049693f.

United States Department of Agriculture Geospatial Data Gateway. Natural Resources Conservation Service. https://gdg.sc.egov.usda.gov/ Accessed January 2006.

US Department of Health and Human Services, Public Health Service, (2015). Agency for Toxic Substances and Disease Registry. Draft toxicological profile for polybrominated diphenyl ethers (PBDEs). 
United Nations Environment Programme (UNEP), 2006. Report of the Persistent Organic Pollutants Review Committee on the work of its second meeting, Addendum, Risk profile on commercial pentabromodiphenyl ether. UNEP-POPS-POPRC.2-17-Add.1.

United Nations Environment Programme (UNEP), 2007. Report of the Persistent Organic Pollutants Review Committee on the work of its third meeting, Addendum, Risk profile on commercial octabromodiphenyl ether. UNEP-POPS-POPRC.3-20-Add.6.

United Nations Environment Programme (UNEP), 2009. The 9 new POPs. Risk Management Evaluations. 2005-2008 UNEP-POPS-POPRC1-POPRC4.

United Nations Environment Programme (UNEP), 2015. Draft risk management evaluation: decabromodiphenyl ether (commercial mixture, c-decaBDE). UNEP-POPS-POPRC.11/2.

Xia, K., Hundal, L.S., Kumar, K., Armbrust, K., Cox, A.E., Granato, T.C., 2010. Triclocarban, triclosan, polybrominated diphenyl ethers, and 4-nonylphenol in biosolids and in soil receiving 33-year biosolids application. Environmental Toxicology and Chemistry 29, 597-605. http://dx.doi.org/10.1002/etc.66.

Wong, F., Kurt-Karakus, P., Bidleman, T. F., 2012. Fate of brominated flame retardants and organochlorine pesticides in urban soil: volatility and degradation. Environmental Science and Technology 46, 2668-2674. http://dx.doi.org/10.1021/es203287x. 
Wolf, B., 1999. The fertile triangle. The interrelationship of air, water, and nutrients in maximizing soil productivity, Food Products Press, The Haworth Press, New York. 
One Month After

Biosolids Application

\section{One Year After}

Biosolids Application
Three Years After

Biosolids Application
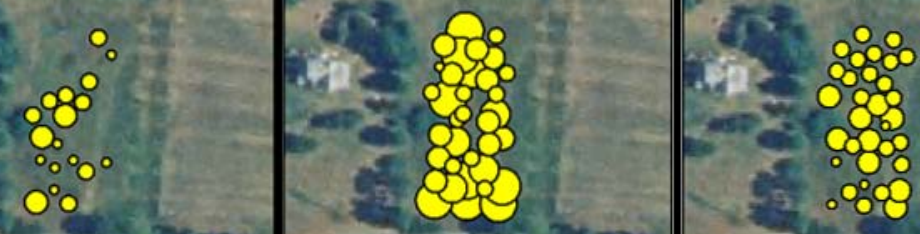

BDE-209 Concentration ( $\mu \mathrm{gkg}^{-1}$ d.w.) 